\title{
Gıda Tedarik Zinciri Yönetiminde Bilgi Teknolojileri Kullanımı
}

\section{Begüm KELEŞ ${ }^{* 1}$, Gülden OVA ${ }^{1}$

\author{
${ }^{1}$ Ege Üniversitesi Mühendislik Fakültesi Gıda Mühendisliği Bölümü, İzmir
}

Öz: Günümüzde firmalar, kurumsal sistemlerini iyi oluşturmaları, iç süreçlerini entegre etmeleri ve faaliyetlerini verimli bir şekilde sürdürmelerinin yanında başarılı olabilmek için tedarik zincirinin bir parçası olarak tüm paydaşlarla etkin bilgi akışı sağlamak zorundadır. Gıda tedarik zincirlerinde; tarladan çatala olan süreçte ortam parametrelerinin gıda güvenliği dolayısıyla insan sağlı̆̆ı açısından yarattı̆̆ı risk, gıdaların kısa raf ömrü ve değişken kalite kriterleri değerlendirildiğinde etkin bir tedarik zinciri yönetimi intiyacı göze çarpar. Bu amaç doğrultusunda bilgi teknolojilerinin kullanımı; gıda tedarik zincirini şeffaflaştırarak izlenebilirliğe olanak vermekte, gıda güvenliği sağlanmakta ve gıda kalitesi korunmaktadır. Bu makalede bilgi teknolojilerinden; kurumsal kaynak planlaması (ERP), radyo frekanslı tanımlama (RFID), nesnelerin interneti (IOT) ve blokzincir sistemlerinin prensipleri ve gıda sektöründeki uygulamaları irdelenmektedir.

Anahtar Kelimeler: ERP, RFID, IoT, blokzincir

Use of Information Technologies in Food Supply Chain Management

Abstract: Nowadays firms must ensure effective flow of information with all stakeholders as a part of the supply chain in order to be successful as well as to establish their corporate systems well, integrate their internal processes and continue their activities efficiently. In food supply chains; in the process from farm to fork, the need for an effective supply chain management is remarkable on account of the ambient parameters pose a risk to human health due to food safety, short shelf life and variable quality criteria of foods. As advantages of information technologies usage; food supply chain will be transparent and enables traceability, food safety will ensure and food quality will maintain. In this article, the principles of enterprise resource planning (ERP), radio frequency identification (RFID), Internet of Things (IoT) and blockchain systems from information technologies and their applications in the food industry are examined.

Keywords: ERP, RFID, IOT, blockchain

\section{GiRiş}

Tedarik zinciri, tüketici için değer üretmek üzere birlikte çalışan paydaşların oluşturduğu organizasyon ağı ve bunların ilişkili faaliyetleridir. Tedarik zinciri yönetimi günümüz küresel pazarında kritik bir yetkinliği temsil etmektedir. Gelişen küresel ekonomide, firmaların potansiyel tedarik zinciri ortakları ile koordineli olarak yeni pazar fırsatlarını, yeni ürünleri ve diğer stratejik iş kararlarını hızlı ve doğru bir şekilde değerlendirme yetenekleri giderek daha fazla önem kazanmaktadır (Zhang ve Li, 2012).

Gıda tedarik zinciri; kaliteli ve güvenli hammaddenin tedariği ile başlayan, gıdanın geçirdiği işlemler, ara ve bitmiş ürün lojistiği ile tüketiciye ulaşmasına kadar geçen süreçte tüm faaliyete ilişkin verileri kapsayan bir bütündür. Gıda tedarik zinciri yönetimi; gıda güvenliği ve kalitesini koruma hedefinde olup, zincir boyunca ürün ve bilgi akışının sorunsuz bir şekilde sürdürülebilirliğini sağlamak amacıyla iş süreçlerinin koordinasyonudur. Gıda tedarik zincirinin doğru bir şekilde yönetilmesi için gereklilikler; paydaşlar arasında etkili iletişim, zincirin teknoloji ve standartlardaki gelişmelere uyum sağlayabilmesi ve etkin bir lojistik yönetimidir (Mahalik ve Kim, 2016).

Gıda kaynaklı sağlık sorunlarının artmasıyla ortaya çıkan gıda güvenliği krizinde tüketicinin sarsılan güveni ve potansiyel riskler tedarik zinciri yönetiminin önemini artırmaktadır (Dianhua ve Douxuan, 2010). Tedarik zinciri yönetimi, bireysel yaklaşım yerine paydaşları, aynı amaç doğrultusunda çalışan bir bütün olarak kabul edip, süreç boyunca her bir işlem için en etkin (kalite, zaman, maliyet vb. bakımından) seçenekte karar kılınmasıdır. Gıda sektöründe fazla sayıda tedarikçi ve müşteriyle çalışıldığından tedarik zinciri geniş olup; insan sağlığı açısından taşıdığı risk, kısa raf ömrü, hassas kalite parametreleri vb. özellikleriyle gıda üretimi diğer sektörlerden ayrılmaktadır. Paydaşların herhangi birinden kaynaklı bir problemin tüm zinciri etkileyerek ürünün kalitesini düşüreceği ve gıda güvenliğini riske atacağı gerçeğiyle zincir bütünlüğünün sağlaması ekstra önem kazanmaktadır (Sezen, 2011). Etkin bir tedarik zinciri yönetimiyle karşılaşılabilecek olası bir sorunda geriye dönülerek problemin kaynağı tespit edilir ve ürünün geri çağrılma süreci hızlandırılmış olur; bu şekilde izlenebilirliğe ışı tutulur. İzlenebilirlik; bir ürünün hammadde tedariğinden başlayıp tüketiciye ulaşmasına kadar olan süreçte dokümantasyon, etiketler, kodlar veya diğer izleme araçlarının veya teknolojilerin kullanımıyla, ürünün tedarik zinciri içerisindeki hareketi ve yerini izleme yeteneğidir. Birçok ülkede yasal bir zorunluluk olarak mevzuatlar kapsamında yer verilen izlenebilirlik kavramının gereklilikleri uluslararası standartlarda da açıklanmıştır

Sorumlu Yazar: begum keles@hotmail.com

Geliş Tarihi: 27 Şubat 2020

Kabul Tarihi: 25 Haziran 2020 
(Cebeci, 2006). Mevzuatımızda, tarım ve gıda ürünleri için firmalara izlenebilirliğin sağlanabileceği bir sistem kurma zorunluluğu getirilmiştir (Anonim, 2010).

Bilgi teknolojileri; verilerin tanımlanması, hesaplanması, iletilmesi ve depolanması için bilgi işlem platformlarının, internet tabanlı iletişim cihazlarının ve protokollerinin kullanımı olarak tanımlanan ağ sistemleridir (Mahalik ve Kim, 2016). Gıda tedarik zinciri yönetiminde kullanılan bilgi teknolojileri; zincir boyunca entegrasyonu kolaylaştırır. Ayrıca, gıda güvenliği standartlarını ve kalite indislerini gerçekleştirirken maliyetlerin de düşürülmesi için kapsamlı bilgi sağlar. Süreç iyileştirmelerini veya yönetim kararlarını destekleyen veriler, tedarik zinciri paydaşlarıyla bilgi paylaşımı ve işbirliği ile gerçekleştirilir. Ayrıca, verilerin kapsamlı ve ayrıntılı verilebilmesi, kullanılan bilgi teknolojisinin yeteneklerine de bağlıdır (Pramatari, 2016). Tedarik zinciri yönetiminde kullanılan bilgi teknolojileri; hammadde eldesinden başlayan işlemleri ürün son tüketiciye ulaşana dek izlerken, paydaşlar ürünün fiziksel yolunu gösteren bilgiye sahip olurlar. $\mathrm{Bu}$ şekilde izlenebilirlik sağlanır, kalite korunur, verimlilik artar. Etkin stok yönetimi, üretim ve lojistik planlamalarıyla zamandan kazanılır, işletme performansı yükselir. Yenilikçi ve teknolojik tedarik zinciri yönetimi işletmeyi rekabette ön plana çıkarır. Herhangi bir aşamadaki paydaş, ürün hakkında detaylı bilgi sahibi olur; gıda güvenliği ve kalitesini sorgulayabilir, şeffaflık artar (Sevinç, 2008).

Bu makalede, gıda tedarik zinciri yönetiminde yaygın olarak kullanılan veya gelişmekte olan bilgi teknolojilerinden kurumsal kaynak planlaması (ERP), radyo frekanslı tanımlama (RFID), nesnelerin interneti (IoT) ve blokzincir sistemlerinin prensipleri ve gıda sektöründeki uygulamaları irdelenmektedir.

\section{Kurumsal Kaynak Planlaması (ERP)}

ERP sistemleri; üretimden lojistiğe, stok kontrolünden kalite yönetimine, finanstan insan kaynaklarına kadar tedarik zinciri sürecinde gerçekleşen tüm faaliyete ilişkin işlem ve verilerin entegrasyonunu sağlayan ticari yazılım paketleridir (Postacı ve ark., 2012). ERP yazılımları; tedarik zinciri paydaşlarının bilgi paylaşımlarına olanak tanır ve izlenebilirliğin sağlanmasında yardımcıdır. Firmaların ihtiyaçlarına göre belirli bir sınıra kadar özelleştirilebilirler. Gıda sektöründe faaliyet gösteren firmalarda karşılaşılan; üretim sürecinde kalite ve maliyet takibi, yetersiz stok kontrolü, standardizasyon eksikliği, farklı lokasyonlar arası bilgi aktarımı problemlerine ERP' nin çözüm getirebileceği belirtilmektedir (Sadrzadehrafiei ve ark., 2013). Gıda sektöründe faaliyet gösteren ve geniş bir dağıtım ağına sahip olan Oetker Grup, en çok rağbet gören ERP yazılımlarından SAP (sistem, uygulamalar, ürünler) modülü kullanıldığı takdirde; lojistikte verimin arttığı, enerji tüketiminin ve kirliliğin azaltıldığını bildirmektedir (Shirazi, 2018).

ERP uygulamaları; firma içerisinde gerçekleşen tüm faaliyete ilişkin parametreleri ilişkilendirerek veri üretir ve işlemleri optimize eder. Örneğin; bir siparişin girişiyle üretim planı oluşturulurken dağıtım planlamaları da yapılır, aynı zamanda stok seviyesi kontrol edilir (Ünlü, 2007). Gıda sektöründe faaliyet gösteren bir firmada ERP yazılımı kullanıldığını düşünürsek; malzeme ve stok yönetimi başlığı altında; satın alma, malzeme giriş-çıkışı, depo ve dağıtım yönetimi yer alabilir. Talebe uygun kapasite planlamalarıyla malzeme ihtiyaçları belirlenip üretim tipi seçilebilir. Aynı zamanda, kalite spesifikasyonları belirlenerek etkin bir kalite yönetimiyle uygunluk kontrolleri yapılabilir.

Sistemin dezavantajları olarak; yüksek kurulum ve değişim maliyeti, bir bölümündeki verimsizliğin diğer bölümleri etkilemesi ve eğitimli personel yetersizliği gösterilebilir (Özdemir ve Doğan, 2010).

\section{Radyo Frekanslı Tanımlama (RFID)}

RFID; ürünlere yerleştirilen özel etiketlerin radyo dalgaları aracılığıyla algılanarak bilgi aktarımı yapılmasını sağlayan bir teknolojidir. RFID sisteminin temel bileşenleri; ürüne ait bilginin depolandığı etiket, etiket ve okuyucu arasındaki iletişimi radyo sinyallerini kullanarak sağlayan anten ve anten aracılığıyla gelen sinyallerle etiket bilgilerini okuyan ve/veya geri sinyal göndererek yeni bilgilerin yazılmasını sağlayan donanımlardır. Okuyucudan gelen bilgiler veritabanında ilişkilendirilir ve kayıt altına alınırlar (Esmer ve Melikoğlu, 2015).

RFID etiketler, hizmet edeceği amaca ilişkin olarak uygun özellikleri taşıyan çeşitlerden tercih edilir. Pasif etiketler; radyo frekans aracılığıyla okuyucudan bilgiyi alır, maliyeti düşüktür ve maksimum 10 metreye kadar okuma yapabilir, örnek uygulama olarak yakın mesafe kartları gösterilebilir. Yarı pasif etiketlerin güç kaynağı bataryadır, pasif etiketten pahalıdır ve 100 metreden fazla okuma yapabilir, elektronik geçiş veya palet izleme uygulama alanı olabilir. Aktif etiketlerin de güç kaynağı bataryadır, maliyeti yüksektir, okuma aralığı 100 metreyi geçer, büyük çapta mal izleme veya hayvan takibinde kullanılabilirler. Pasif ve yarı pasif etiketler ancak bir okuyucu tarafından sorgulandıklarında etkinleşirler; dolayısıyla sadece yanıt verebilirler. Aktif etiketler ise okuyucu veya diğer aktif etiketlerle ilk iletişime geçebilirler. Bu şekilde, yanıt verebilirken iletişimi de başlatabilirler. RFID etiketlerinin okuma mesafesinin ve etiketler arası iletişim tipinin belirlenmesinde frekans seçimi önemlidir. Farklı boyut ve şekillerdeki antenler farklı frekanslarda çalışır. Çalışılan frekanslar; düşük, yüksek, ultra yüksek, mikrodalga ve ultra geniş bant olarak sıralanabilir (Weis, 2011). 
RFID teknolojisinin gıda sektöründeki uygulamaları; tedarik zinciri yönetimi, sıcaklığın izlenmesi ve gıda güvenliğinin sağlanması konularında yoğunlaşmıştır (Kumar ve ark., 2009). RFID, ürünlerle iletişime geçmek için görüş mesafesine gerek duymadığından, aynı anda çok sayıda etiketin (kirlilik durumunda veya görünür olmasa dahi) okunmasına olanak tanımaktadır. Bu sistem, veri aktarımını otomatikleştirerek güncellemelere imkan vermekte ve tedarik zinciri boyunca ürün takibinde fayda sağlamaktadır. Gıda tedarik zincirinde; üründe gerçek zamanlı görünürlükle sıcaklık, su içeriği vb. ürün parametreleri takibi sayesinde gıda güvenliği sorgulanabilmektedir. Böylece sistem, gıda izlenebilirliğini etkin kılar, zincirin verimliliğini artırır (Zhang ve Li, 2012). RFID teknolojisinin gıda sektöründeki tedarik zinciri yönetimine ilişkin uygulamalarına Çizelge 1 ' de yer verilmiştir.

Özellikle çabuk bozulan hassas gıdalarda (et, süt, meyve vb.) ürünün ve bulunduğu ortamın sıcaklığını ölçebilen sıcaklık sensörlü RFID etiketler aracılığıyla gıda ürünlerinin takibi sağlanmaktadır. Örneğin; Infratab (ABD) tarafından üretilen Freshtime $^{\mathrm{TM}}$ yarı pasif RFID etiketleri, gıdanın raf ömrünü izleyebilmek amacıyla algıladığı sıcaklık değerlerini zamana entegre eder. Ayrıca, ürünün durumuna göre değişkenlik gösteren (taze için yeşil, tehlike için kırmızı vb.) görsel ekran aracılığıyla takip yeteneğini güçlendirir. Gıda güvenliğini sağlamak amacıyla yapılan farklı bir projede; RFID teknolojisi gıdalardaki patojenleri algılayan sensörlerle kombine edilmiştir. Patojen kontaminasyonu durumunda bağlı RFID okuyucusuna sinyal iletilmektedir (Kumar ve ark., 2009).

Gıda alanında RFID teknolojisiyle yapılmış deneysel çalışmalarda ışık, sıcaklık, nem ve oksijen/karbondioksit gaz sensörlü ya da belirlenen referans ölçüm değerleri aralığında dielektrik özellikleri algılayan pasif/yarı pasif veya aktif RFID etiketler kullanılarak tedarik zincirinde izlenebilirlik sağlanmıştır (Esmer ve Melikoğlu, 2015).

RFID teknolojisinin yaygınlaşması önündeki temel engeller; standartların olmayışı, etiket maliyetleri ve teknik yetersizliktir (Esmer ve Melikoğlu, 2015). Mevcut ticari ve deneysel uygulamalarla kendini kanıtlamış olan bu teknolojinin yaygınlaşması için yapılacak çalışmalar, gıda tedarik zinciri yönetiminin etkinleştirilmesini sağlayacaktır.

\section{Nesnelerin İnterneti (IoT)}

Nesnelerin interneti (IoT); nesnelerin çeşitli iletişim ağları ve algılama yöntemleri aracılığıyla tanımlanarak ürettiği bilgiyi birbirine aktarabilen akıllı cihazlardan oluşan bir teknolojidir (Evgen, 2017).

Nesnelerin interneti teknolojisinde kullanılan nesneler, tanımlanabilir olmalı ve iletişim kurabilmelidir. Dolayısıyla, nesneleri tanımlamak için radyo dalgalarını kullanan RFID etiketleri bu teknoloji için temel oluşturur (Khalil ve Özdemir, 2018). IoT ile ilişkili nesnelerin çoğu sensör tabanlı sistemlerdir. Nesnelere veri toplayabilmesi için gerekli sensörler yerleştirilir. İzlenilmesi amaçlanan özelliği algılama yeteneğine sahip olan sensör seçimiyle (RFID etiketleri, yakın alan iletişimi (NFC) sensörleri vb.) ilk veriler elde edilir. $\mathrm{Bu}$ veriler; sıcaklık, konum, ağırıı, nem, basınç, sertlik, pH değeri, karbondioksit oranı, ışık şiddeti vb. olabilir. Başlangıçta, ölçülebilir büyüklükler ham veri durumundadır. Ham veriler algılanarak analog ve sayısal sinyallere dönüştürülür. Sinyaller, kablosuz bağlantılar aracılığıyla iletilir, veri işleme merkezinde işlenir, analiz edilir ve kullanılır (Gökrem ve Bozuklu, 2016). İnternet erişiminin artması ve sensör teknolojisinin gelişimine ek olarak, bulut bilişim, mobil cihazların ve ağların kullanılabilirliği ıoT teknolojilerinin uygulanmasında artış yaratmıştır. Bu donanımda en yaygın kullanılan kablosuz iletişim teknolojileri; mobil cep telefonu ağları, Wi-Fi, Bluetooth, ZigBee, GPRS olarak sıralanabilir (Gülşen, 2019).

Çizelge 1. RFID teknolojisinin gıda sektöründeki tedarik zinciri yönetimine ilişkin uygulamaları

\begin{tabular}{|c|c|}
\hline Firma & Uygulama \\
\hline Wallmart (ilk uygulama) & $\begin{array}{l}\text { İzlenebilirliği sağlamak amacıyla tedarikçilerinden elektronik ürün kodu içeren RFID etiketli } \\
\text { paletler istemiştir (Jones ve ark., 2015). }\end{array}$ \\
\hline $\begin{array}{l}\text { British } \\
\text { Telecommunications } \\
\text { (BT Foodnet) }\end{array}$ & $\begin{array}{l}\text { Perakendeci ve tedarikçilerin, üreticiden satış noktasına kadar tüm stok ürünlerin geçmiş ve } \\
\text { mevcut durumu hakkında gerçek zamanlı verilere erişimini sağlayan RFID teknolojisine dayalı } \\
\text { çevrimiçi gıda izlenebilirlik sistemi geliştirilmiştir (Connolly, 2007). }\end{array}$ \\
\hline $\begin{array}{l}\text { Unilever ve } \\
\text { Metro Future Store }\end{array}$ & $\begin{array}{l}\text { Depodaki ürünleri taşımak, işlemek ve izlemek amacıyla RFID teknolojisini kullanır } \\
\text { (Loebbecke, 2005). }\end{array}$ \\
\hline eProvenance & $\begin{array}{l}\text { İyi şarapların kalitesini korumak ve menşeini izlemek için RFID tabanlı izlenebilirlik sistemi } \\
\text { geliştirilmiştir (Kumar ve ark., 2009). }\end{array}$ \\
\hline United Biscuits & $\begin{array}{l}\text { Bisküvi ve keklerin hazırlanmasında yer alan tartım, karıştırma, fırınlama işlemlerinde ve } \\
\text { hammaddelerin hareketini kontrol etmede RFID teknolojisini kullanır (Angeles, 2005). }\end{array}$ \\
\hline $\begin{array}{l}\text { İtalyan Parmesan } \\
\text { peyniri üreticileri }\end{array}$ & $\begin{array}{l}\text { Tedarik zinciri boyunca peynir izlenebilirliğini sağlamak amacıyla oluşturulan RFID tabanlı } \\
\text { sistemde tüketici, alfanumerik kod satın alarak web sitesi üzerinden peynirin tüm geçmişine } \\
\text { ulaşabilir (Regattieri ve ark., 2007). }\end{array}$ \\
\hline
\end{tabular}


IoT teknolojisinin gıda tedarik zincirine entegrasyonuyla; gıda güvenliği sağlanması ve kalite kriterleri izlenebilirliği amaçlanmaktadır (Çaylı, 2019). Merkezi veri toplama ve analitiklerin yardımıyla, IoT tabanlı mekanizmalar gıda israfını önemli ölçüde azaltabilir, lojistik ve dağıtım verimliliğini artırabilir ve kontamine veya bozulmuş ürünlerin taze gıda tedarik zincirinden hızlı bir şekilde çıkarılmasını sağlayabilir (Pal ve Kant, 2018).

IoT teknolojisi tarımda; ağır metaller, tarım ilacı kalıntısı vb. istenmeyen maddelerin analizi, sulama otomasyonu, gübreleme, haşere kontrolü vb. için uygulama zamanlarının bildirimi, toprağın sıcaklık ve nem kontrolleri, seralardaki ortam koşullarının takibi, gerçek zamanlı ürün ve kaynak analiziyle çiftçinin ekimden hasada kadar tüm faaliyetinin izlenebilirliği vb. amaçlar doğrultusunda kullanılmaktadır. Hayvanclıkta ise; çiftlik hayvanlarının sağlığının izlenmesi, hastalıkların erken teşhisi, fizyolojik, davranış ve üretkenliğin takibi gibi uygulamalar uzun vadede daha kaliteli hayvansal ürün elde edilmesine yardımcı olmaktadır (Comart ve ark., 2018).

Lu ve Wang (2016) yılında yaptıkları çalışmada soğuk zincir endüstrisindeki bozulabilir gıda ürünlerinin (meyve, sebze, et, dondurulmuş tatlılar vb.) kalite kontrolünü geliştirmek için bulut bilişim tabanlı loT sistemi geliştirmişlerdir. Kritik veriler bulut tabanlı veritabanı sisteminde toplanır, iletilir ve saklanır. Soğutmalı araçların hızı ve konumu takip edilerek gerçek zamanlı ve geçmiş veriler dijital haritada görüntülenir. Gıda ürünlerinin depodaki durumları belirlenerek gıdalara ilişkin gerçek zamanlı veriler analiz edilir ve ortam koşulları takip edilir. Soğuk zincir boyunca gıdaların fiziksel akışı izlenerek belirlenen değerlerin dışına çıkıldığında bildirim mesajlarının ilgili kullanıcıya gönderilmesi sağlanır. Bu sistemde, depolama ve lojistik sürecinde gıda ürünlerinin gerçek zamanlı durumunun izlenmesi; ortam koşullarının analizi, sıcaklık ihlali ve rota sapması gibi risklerin zamanında tespit edilebilmesine olanak verdiğinden gıda güvenliği sağlanmış olup gıda kalitesi korunmuştur.

Maksimović ve ark. (2015) tarafından yapılan bir çalışmada lojistik sırasında gıdaların izlenebilirliği için gerçek zamanlı erişim sağlayan, ekonomik, sensör tabanlı bir loT sistemi önerilmiştir. Sistemde, sıcaklık ve nemi algılayan sensörler kullanılmış olup, izlenecek gıdaya özgü gereksinimlere bağlı olarak ek sensörler dahil edilebilir. Bu araştırmada, gıdaların lojistik araçlarına yüklenmesinin ardından verilerin elde edilmesi için RFID kullanılmış olup, NFC veya bluetooth da kullanılabileceği bildirilmektedir. Elde edilen veriler merkezi izleme sistemine (CMS) iletilmekte ve GSM/GPRS modülü üzerinden internet aracılı̆ı̆yla lojistik sırasında takip sağlanabilmektedir. Bu aşamada, düşük maliyetli bir bilgisayar kartı; sensör verilerine erişen ve son kullanıcılarla iletişim kuran merkezi bir işlem birimi olarak görev almaktadır. Farklı sensör türleri ise (hedef parametreye bağıı olarak) algılama modülünü oluşturmaktadır.

Culman ve ark. (2017) yılında palm yağı işletmesinde toprak koşullarının kontrolü için loT tabanlı PalmNET ismini verdikleri bir çözüm üretmişlerdir. PalmNET otomatik olarak toprak nemi verilerini toplayabilmekte ve saha verilerini kısa menzil için ZigBee, uzun menzil için GPRS ağı üzerinden bir web sunucusuna aktarabilmektedir. Sunucular, verilerin görüntülenmesi için kullanılan ara yüzlerdir. Bu şekilde kullanıcılar, gerçek zamanlı veri toplayabilir, değerlendirebilir ve depolayabilir.

Nesnelerin interneti, yeni bir teknoloji olmakla birlikte yapılan çalışmalar incelendiğinde umut vadeden bir sistem olduğu açıktır. Bu sistemde, maliyet, teknik yetersizlik, standart eksikliği ve veri güvenliği gibi engeller aşıldığı takdirde yeni iş modelleri yaygınlaşarak tedarik zinciri paydaşlarına fayda sağlanacaktır (Çaylı, 2019). Sistemin gıda tedarik zincirinde uygulamalarının yaygınlaşmasıyla üretimden tüketime gıda kalitesinin artması ve kaynaklar verimli bir şekilde kullanılmasının mümkün olacağı düşünülmektedir.

\section{Blokzincir}

Blokzincir; ağ ortamında onaylanmış kullanııılar tarafından şifrelenen verilerin değişmez bir dağıtık veritabanına kaydedilerek tüm kullanıılar tarafından eş zamanlı takibinin sağlandığı teknolojidir (Kaya ve Turğut, 2019).

Blokzincir teknolojisinde işleyiş; tedarik zincirindeki tüm paydaşların kendini sisteme kaydetmesiyle başlar; benzersiz kimlik ve dijital profiller sistemde eşleşir. Her kullanıı için anahtar çiftleri oluşturulur. Her bir paydaş tarafından yeni bir işlem yaratıldığında bu değişikliğin algılanması ve zincirdeki paydaşların belirli prosedürleri dikkate alarak bu işlemi onaylamasıyla zincire yeni bir blok eklenir. Tedarik zinciri boyunca ürün eklenmesi ve güncellenmesi durumunda taraflarca akıllı sözleşmeler imzalanır. Bu işlemler anahtar çiftleriyle gerçekleştirilir (Tian, 2017).

Blokzincirin, tedarik zinciri yönetiminde karşılaşılan sorunlara getirdiği yenilikçi çözümler; merkezi olmayan yapısı, güvenliği, denetlenebilirliği ve akıllı uygulama olmasıdır (Saberi ve ark., 2018). Tedarik zinciri boyunca sonsuz bilgi kaydı ve paydaşlar tarafından eş zamanlı izlenebilirlik, denetlenebilirliğin ölçütüdür. Veri kaynağının bütünlüğünde işlemlerin sisteme eş zamanlı geçişi ve kurcalamaya dayanıkı oluşu, değişmez ve güvenli olduğunun göstergesidir. Maliyeti artırmadan tedarik zincirindeki olası değişikliklere hızlı bir şekilde adaptasyon sağlanması, taraflarca imzalanan akıllı sözleşmelerle mümkündür. Tedarik zinciri paydaşları arasında dijital imzalar güvencesiyle birebir iletişim sağlandığından aracılar da ortadan kaldırılmış olur (Kehoe ve ark., 2017). 
Gıda tedarik zinciri yönetiminde; paydaşlar arası iletişimi güçlendirmek ve gıdanın izlenebilirliğini sağlamak amacıyla blokzincir teknolojisi kullanılarak endüstriyel bir platform oluşturulabilir. Yeni bir tedarikçiyle işe başlama veya devam eden iş ilişkileri için tedarikçilerle akıllı sözleşmeler imzalanabilir. Gıda tedarik zincirine ait detaylarda gıdanın hareketi izlenebilir, bu şekilde gıda güvenliği ve kalitesi sorgulanabilir. Onaylanmış kalite sertifikalarıyla ürün orijinalliği kanıtlanabilir. Paydaşlar tarafından eklenen veya güncellenen verilerle sistem canlı tutulur (Kehoe ve ark., 2017).

Blokzincir teknolojisinin gıda sektöründeki uygulamalarına Çizelge 2' de yer verilmiştir (Antonucci ve ark., 2019; Kshetri, 2018).

Gıda sektöründe blokzincir teknolojisi kullanılarak yapılan projeler ve uygulamalarda, tedarik zincirindeki paydaşlar sisteme entegre edilmektedir. Bu şekilde, güvenli gıda üretimi ve dağıtımını sağlayabilmek için kanıtlanmış ve güvenilir bir ortam oluşturulmaktadır. Blokzincir, farklı teknolojilerle (RFID, loT vb.) kombine edilmekte, bu şekilde gıda tedarik süreçleri daha şeffaf olmakta ve yüksek otomasyonla izlenebilmektedir (Kamilaris ve ark., 2019).
Yılmaz (2019) tarafından yapılan bir çalışmada gıda tedarik zincirinde ürünlerin tedarikçiden tüketiciye ulaşmasını takip edecek bir blokzincir sistemi tasarlanmıştır. Örnek uygulamada muzun tedarikçiden tüketiciye şehirlerarası taşınması takip edilmiştir. Tedarikçi, taşımacı ve satış noktasından oluşan sistem, gıda ürünlerinin taşıma esnasındaki sıcaklık koşullarının kayıtlanması ve teslim sonucu ürün kabulünde para alışverişinin akıllı sözleşme ile gerçekleşmesini sağlamaktadır. Bu sistemde, blokzincir ile kombine edilen teknoloji taşıma sırasında muz sıcaklığını ölçen loT türü endüstriyel termometrelerdir.

Blokzincir yapısından dolayı; kalite, güvenilirlik, hız, maliyet, risk azaltma, sürdürülebilirlik ve esneklik gibi anahtar tedarik zinciri yönetimi hedeflerine ulaşmada etkilidir (Kshetri, 2018). Öncü kuruluşların blokzincirin standardizasyonu için yaptıkları hazırlıklar, danışmanlık şirketlerinin teknolojiyi kullanmak isteyen firmalara sağladığı teknik ve stratejik destek, yazılım firmalarının blokzincir tabanlı altyapılar ve uygulamalar geliştirmesi, blokzincir araştırma laboratuarları kurulması; bu teknolojinin yaygınlaşacağının göstergesi olarak yorumlanabilir (Ünsal ve Kocaoğlu, 2018).

Çizelge 2. Blokzincir teknolojisinin gıda sektöründeki uygulamaları

\begin{tabular}{|c|c|}
\hline Firma & \\
\hline Wallmart & $\begin{array}{l}\text { Blokzincir tabanlı bir sistem olup izlenebilirliğe olanak sağlayan IBM Food Trust yazılımını } \\
\text { kullanmaktadır. Gıda ürünlerinin geçmişine ve sertifikalarına ait bilgiler sorgulanabilir. }\end{array}$ \\
\hline Provenance & $\begin{array}{l}\text { Balıklar, denizden ton balığı konservesine kadar blokzincirde doğrulanmış sürdürülebilirlik } \\
\text { bilgileriyle izlenebilmektedir. }\end{array}$ \\
\hline Intel Sawtooth Lake & Balıkçılardan restoranlara kadar olan süreçte balığa ilişkin bilgiler blokzincirde kaydedilir. \\
\hline Everledger & $\begin{array}{l}\text { Şarapların hareketinin izlendiği blokzincir tabanlı sistemde dijital veriler güncellenir ve } \\
\text { depolama bilgileri kaydedilir. }\end{array}$ \\
\hline Downstream & $\begin{array}{l}\text { Bira üretiminde mayalama yöntemleri ve bileşenlerle ilgili bilgileri ortaya koymak için } \\
\text { blokzincir teknolojisi kullanılmaktadır. }\end{array}$ \\
\hline Aldo Cozzi & $\begin{array}{l}\text { Makarnaların tedarik zincirine ait bilgiler (üretici, ürünler, kullanılan un,kurutma tipi, lojistik } \\
\text { vb.) blokzincir tabanlı bir sistemde tanımlanmaktadır. }\end{array}$ \\
\hline CyberSecurity & $\begin{array}{l}\text { Süte ait tedarik zincirinde elde edilen verilerin blokzincir tabanlı sistemde otomatik } \\
\text { işlenmesiyle gıda hilelerinin önüne geçilmesi amaçlanmaktadır. }\end{array}$ \\
\hline San Domenico Coffee & $\begin{array}{l}\text { Fidanlıktan fincana kadar olan süreçte kahvenin izlenebilirliği blokzincirin mutlak şeffaflık } \\
\text { garantisiyle sağlanmaktadır. }\end{array}$ \\
\hline JD & $\begin{array}{l}\text { Sığır eti odaklı çalışan blokzincir tabanlı sistemin tedarik zincirine entegrasyonuyla gıda } \\
\text { hilelerinin önüne geçilmeye çalışılmaktadır. }\end{array}$ \\
\hline Arc-net & $\begin{array}{l}\text { Alkollü içkiler için damıtma, tarım ürünleri için hasat odaklı blokzincir tabanlı izlenebilirlik } \\
\text { sağlanmaktadır. }\end{array}$ \\
\hline Ripe.io & $\begin{array}{l}\text { Sensör verilerinden faydalanılarak gıdanın kaynağına ait veriler blokzincir tabanlı sisteme } \\
\text { işlenerek tarladan çatala şeffaflık sağlanmaktadır. }\end{array}$ \\
\hline \multicolumn{2}{|c|}{$\begin{array}{ll}\text { SONUÇ } & \text { personelinin eğitim ve yetkinlik düzeyi vb. birçok faktörü } \\
\text { 21. yüzyıl koşullarında, bilgi akışına yön vererek tedarik } & \text { göz önünde bulundurmalıdır. Örneğin; küçük işletmeler } \\
\text { zinciri yönetiminin etkinleştirilmesinin ancak bilgi maliyet ve teknik yetersizliklerden dolayı Word, Excel, e- } \\
\text { teknolojileriyle mümkün olacağı görülmektedir. Firmalar, } & \begin{array}{l}\text { mail vb. basit uygulamalara yönelmektedir. Firma } \\
\text { hangi teknolojileri kullanacaklarına ve kendi tedarik }\end{array} \text { büyüklüğü arttıkça kullanılan bilgi teknolojileri } \\
\text { zincirlerine nasıl entegre edeceklerine karar verme } & \text { gelişmektedir. Elde edilecek ürünün özelliklerine ve } \\
\text { aşamasında; işletmenin büyüklüğü, maliyet, mevcut altyapı } & \text { sürecine uygun parametreler ve tedarik zincirindeki kilit } \\
\text { türleri, zincirdeki paydaşlarının kullandıkları iletişim araçları, noktalar belirlenerek amaca uygun teknoloji seçimi }\end{array}$} \\
\hline
\end{tabular}


yapılabilmektedir. Tedarik zinciri yönetiminde bilgi teknolojileri kullanmaya karar veren bir firmayı değerlendirirsek; işletme içi fonksiyonların entegrasyonunda ERP yazılımları veya RFID uygulamalarıla başlangıç önerilebilir. Kurulan düzen ve yetişmiş personellerle işletme içi ve dışı kullanılmak üzere loT ya da blokzincir teknolojilerine geçiş amacıyla Ar-Ge çalışmaları yürütülebilir. Tedarikçiler; firmaların iş ortaklarıdır. Dolayısıyla; firmalar tedarikçilerine sistem kurma zorunluluğu getirerek ve destek vererek iletişimi güçlendirmelidir. Yeni teknolojilerin getirdiği faydaların yanında engeller çıkması kaçınılmazdır, teknolojiden sağlanacak verimi artırmak için engeller üzerine çalışılmalı ve iyileştirmeler yapılmalıdır.

Gıda güvenliği günümüzde temel bir sorundur. Bu nedenle, gıda tedarik zinciri boyunca gıda ürünlerinin izlenebilirliğini sağlayan bir sisteme sahip olmak çok önemlidir. Gıda ürünlerinin tedarik zinciri sürecinde geçirdiği işlemlerin ve maruz kaldığı koşulların takibi, kullanılan katkı maddeleri ve kimyasalların denetimi, kontaminasyon tespiti vb. avantajlar bilgi teknolojileri kullanımıyla sağlanabilir. Bu şekilde, işletme kontrolü ve üretim planlamaları kolaylaşırken; olası bir sorunda problemin kaynağının saptanarak hataların tekrarlanması önlenir ve uygunsuz ürünler piyasadan hızlı bir şekilde çekilerek tüketici sağlığı korunur. Ayrıca, aldığı ürünün geçmişine ait bilgilere erişebilen tüketici gıda güvenliğini sorgulayabilir ve kalitesinden emin olur.

Gıda sektöründe faaliyet gösteren firmalar; mevzuattaki zorunluluklarını yerine getirerek, tarladan çatala izlenebilirliğin sağlanmasına olanak tanıyan yeni teknolojileri kullanmaya başlamalı; tedarik zincirlerini şeffaflaştırarak tüketici taleplerine yanıt vermelidir. Bilgi teknolojilerinin tedarik zincirine entegrasyonu noktasında var olan engellerin aşılması ve farklı teknolojilerin kombine kullanımlarının değerlendirilerek verimin artırılması amacıyla yapılacak çalışmalarda araştırmacılara büyük görev düşmektedir. Bilgi teknolojileri kullanımının yaygınlaştırılması ve farkındalık yaratılması için projeler geliştirilmeli ve desteklenmelidir.

\section{KAYNAKLAR}

Angeles R (2005) RFID Technologies: Supply-Chain Applications and Implementation Issues. Information Systems Management 22(1): 61-65.

Anonim (2010) Veteriner Hizmetleri, Bitki Sağlığı, Gıda ve Yem Kanunu, Kanun No: 5996, 13.06.2010 tarihli ve 27610 sayılı Resmi Gazete.

Antonucci F, Figorilli S, Costa C, Pallottino F, Raso L, Menesatti P (2019) A Review on Blockchain Applications in the Agri-Food Sector. Journal Science Food Agriculture 99 (2019): 6129-6138.
Cebeci Z (2006) Gıda İzlenebilirliğinde Bilgi Teknolojileri. Ulusal Tarım Kurultayı, 15-17 Kasım 2006. Çukurova Üniversitesi, Adana, Bildiriler: 189-195.

Comart A, Oral O, Çağlayan N (2018) Nesnelerin İnterneti Teknolojisinin Tarımsal Alandaki Uygulamaları. Uluslararası Hakemli Mühendislik ve Fen Bilimleri Dergisi, 13 (2018): 11-34.

Connolly C (2007) Sensors Trends in Processing and Packaging of Foods and Pharmaceuticals. Sensor Review 27(2): 103-108.

Culman M, Portocarrero J, Guerrero DC, Bayona C, Torres L, Farias MC (2017) PalmNET: an Open-Source Wireless Sensor Network for Oil Palm Plantations. IEEE $14^{\text {th }}$ International Conference on Networking, Sensing and Control, Italy.

Çaylı A (2019) Nesnelerin İnterneti ve Tarımsal Uygulamaları. ISAS 2019, SETSCI Conference Proceedings 4(1): 113-120.

Dianhua W, Douxuan H (2010) Food Supply Chain Management Under Conditions of Food Safety. 2010 International Conference on Management and Service Science.

Esmer Ö, Melikoğlu A (2015) Gıda Güvenliğinin Sağlanmasında Radyo Frekanslı Tanımlama Teknolojisinin Rolü. Akademik Gıda 13(1): 72-80.

Evgen T (2017) RFID ve Nesnelerin İnterneti Tabanlı Tedarik Zinciri Bilgi Yönetimi. Dönem Projesi, Pamukkale Üniversitesi Fen Bilimleri Enstitüsü, Denizli.

Gökrem L, Bozuklu M (2016) Nesnelerin İnterneti: Yapılan Çalışmalar ve Ülkemizdeki Mevcut Durum. Gaziosmanpaşa Bilimsel Araştırma Dergisi 13: 47-68.

Gülşen i (2019) Nesnelerin İnterneti: Vaatleri ve Faydaları. Avrasya Sosyal ve Ekonomi Araştırmaları Dergisi 6 (8): 106-118.

Jones P, Clarke-Hill C, Comfort D, Hilliear D, Shears P (2005) Radio Frequency Identification and Food Retailing in the UK. British Food Journal 107(6):356-60.

Kamilaris A, Fonts A, Prenafeta-Boldú XF (2019) The Rise of Blockchain Technology in Agriculture and Food Supply Chains. Trends in Food Science \& Technology 91 (2019): 640-652.

Kaya S, Turğut M (2019) Tedarik Zincirinde Blok Zincir (Blockchain) Teknolojisi. The Journal of International Scientific Researches, 4 (2): 121-134.

Kehoe L, O'Connell N, Andrzejewski D, Gindner K, Dalal D (2017) When Two Chains Combine: Supply Chain Meets Blockchain. Deloitte: 2-15.

Khalil AE, Özdemir S (2018) Nesnelerin Internetine Genel Bir Bakış: Kavram, Özellikler, Zorluklar ve Fırsatlar. Pamukkale Üniversitesi Mühendislik Bilimleri Dergisi 24(2): 311-326.

Kshetri N (2018) Blockchain's Roles in Meeting Key Supply Chain Management Objectives, International Journal of Information Management 39 (2018): 80-89.

Kumar P, Reinitz WH, Simunovic J, Sandeep PK, Franzon DP (2009) Overview of RFID Technology and Its 
Applications in the Food Industry. Journal Of Food Science, 74 (8): 101-106.

Loebbecke C (2005) RFID Technology and Applications in the Retail Supply Chain: The Early Metro Group Pilot. 18th Bled Conference Integration in Action, Slovenia: $1-11$.

Lu S, Wang X (2016) Toward an Intelligent Solution for Perishable Food Cold Chain Management. 7th IEEE International Conference on Software Engineering and Service Science, China.

Mahalik N, Kim K (2016) The Role of Information Technology Developments in Food Supply Chain Integration and Monitoring. Innovation and Future Trends in Food Manufacturing and Supply Chain Technologies: 21-37.

Maksimović M, Vujović V, Mikličanin OE (2015) A Low Cost Internet of Things Solution for Traceability and Monitoring Food Safety During Transportation. $7^{\text {th }}$ International Conference on Information and Communication Technologies in Agriculture, Food and Environment, Greece: 583-593.

Pal A, Kant K (2018) loT-Based Sensing and Communications Infrastructure for the Fresh Food Supply Chain. IEEE Computer Society: 76-80.

Postacı T, Belgin Ö, Erkan ET (2012) KOBİlerde Kurumsal Kaynak Planlaması (ERP) Uygulamaları. T.C. Sanayi, Bilim ve Teknoloji Bakanlığı Verimlilik Genel Müdürlüğü Yayın No: 723, Ankara.

Pramatari K (2016) Information Technology for Food Supply Chains, Supply Chain Management for Sustainable Food Networks: 183-203.

Regattieri A, Gamberi M, Manzini R (2007) Traceability of Food Products: General Framework and Experimental Evidence. Journal of Food Engineering 81 (2007): 347356.

Saberi S, Kouhizadeh M, Sarkis J, Shen L (2018) Blockchain Technology and Its Relationships to Sustainable Supply Chain Management, International Journal of Production Research 57 (7): 2117-2135.

Sadrzadehrafiei S, Chofreh GA, Hosseini KN, Sulaiman R (2013) The Benefits of Enterprise Resource Planning (ERP) System Implementation in Dry Food Packaging Industry. The 4th International Conference on
KELEŞ B, OVA G

Electrical Engineering and Informatics, Procedia Technology 11 (2013):220 - 226.

Sevinç N (2008) Tedarik Zinciri Yönetiminde Bilgi Teknolojilerinin Kullanılması ve Önemi. Yüksek Lisans Tezi, Trakya Üniversitesi Sosyal Bilimler Enstitüsü, Edirne.

Sezen G (2011) Gıda Zincirlerinde Dağıtım Ağı Tasarımı: Hollanda' da Bir Uygulama. Yüksek Lisans Tezi, Adnan Menderes Üniversitesi Sosyal Bilimler Enstitüsü, Aydın.

Shirazi B (2018) Towards a Sustainable Interoperability in Food Industry Small \&Medium Networked Enterprises: Distributed Service-Oriented Enterprise Resources Planning. Journal of Cleaner Production 181 (2018): 109-122.

Tian F (2017) A Supply Chain Traceability System for Food Safety Based on HACCP, Blockchain \& Internet of Things. Department of Information Systems and Operations Vienna University of Economics and Business Vienna, Austria.

Özdemir IA, Doğan Ö (2010) Tedarik Zinciri Entegrasyonu ve Bilgi Teknolojileri. Sosyal Bilimler Enstitüsü Dergisi, 28 (1): 19-41.

Ünlü FZ (2007) Tedarik Zinciri Yönetimi, Lojistik ve Taşımacılıkta Bilişim Teknolojileri ve Uygulamaları. Yüksek Lisans Tezi, İstanbul Teknik Üniversitesi Fen Bilimleri Enstitüsü, İstanbul.

Ünsal E, Kocaoğlu Ö (2018) Blok Zinciri Teknolojisi: Kullanım Alanları, Açık Noktaları ve Gelecek Beklentileri. Avrupa Bilim ve Teknoloji Dergisi 13: 54-64.

Yılmaz R (2019) Ürünlerin Tedarikçiden Tüketiciye Ulaşmasını Takip Edecek Bir Blok Zinciri Sisteminin Tasarlanması. Yüksek Lisans Tezi, İstanbul Üniversitesi Fen Bilimleri Enstitüsü, İstanbul.

Zhang M, Li P (2012) RFID Application Strategy in Agri-Food Supply Chain Based on Safety and Benefit Analysis. 2012 International Conference on Solid State Devices and Materials Science, Physics Procedia 25 (2012): 636- 642 .

Weis AS (2011) RFID (Radio Frequency Identification): Principles and Applications. MIT Computer Science \& Artificial Intelligence Laboratory. 
